\title{
Influence of Anemia on Plasmodium falciparum Gametocyte Sex Ratios in Acutely Symptomatic Children
}

\author{
Akintunde Sowunmi*, Sulayman T. Balogun, Grace O. Gbotosho and Christian T. Happi \\ Department of Pharmacology \& Therapeutics and Institute for Medical Research and Training, University of Ibadan, \\ Ibadan, Nigeria
}

\begin{abstract}
Anemia is common in African children but little is known about how malarial anemia influences Plasmodium falciparum gametocyte sex ratios (PfGSR) and transmission in endemic areas in Africa. We investigated the changes in PfGSR in 1126 consecutive children with acute, symptomatic, uncomplicated falciparum malaria who did $(\mathrm{n}=99)$ or did not $(n=1027)$ have anemia (defined as a hematocrit $<25 \%)$ and who were treated with various antimalarial drugs in an endemic area of southwest Nigeria. On presentation, anemic children were significantly younger and had a significantly higher PfGSR $(0.28 \pm 0.07$ (se) $v 0.15 \pm 0.02, \mathrm{P}=0.044)$. In anemic, but not in non-anemic children, a duration of illness $>3 \mathrm{~d}$ was associated with a male-biased sex ratio (defined as PfGSR $\geq 0.5)(\mathrm{P}=0.029)$. Hematocrit correlated negatively with PfGSR in non-anemic but not in anemic children $(r=-0.219, \mathrm{P}=0.027$ and $\mathrm{r}=-0.106, \mathrm{P}=0.697$, respectively) suggesting that the critical hematocrit producing 'all or none effect' on PfGSR was a value below 25\% in this cohort of children. Temporal changes showed that, in general, in anemic children, PfGSR was significantly higher at enrolment than in non-anemic children treated with chloroquine (CQ), amodiaquine (AQ) and amodiaquine-sulfalene-pyrimethamine (ASP) ( $P<0.0007$ in all cases), and remained significantly higher by day 7 or 14 in those treated with AQ and pyrimethaminesulfadoxine plus probenecid (PSP) ( $\mathrm{P}<0.007$ in all cases). In children who received the same treatment, the ratio of the sex specific half-life male:female, the 'gametocyte maleness index', was one and a half to two folds higher in anemic than non-anemic children suggesting anemia prolongs the survival of microgametocytes and may encourage transmission. These findings have implications for malaria control efforts in endemic sub-Saharan countries where malarial anemia is common.
\end{abstract}

Key Words: $P$. falciparum, anemia, gametocytes sex ratio, transmission, antimalarials, children, Nigeria.

\section{INTRODUCTION}

Anemia is common in African children and is multifactorial in origin [1]. In these children, falciparum malaria is an important cause of acute and a major contributor to chronic anemia [2,3]. In African children with acute P. falciparum infections, gametocyte carriage varies from 8-17\% [46]. In these children, many variables contribute to the risk for gametocyte carriage amongst which is anemia [5].

Many variables, for example, high gametocyte density, a male biased sex ratio, antimalarial drugs or sensitivity to drugs have been shown to enhance gametocyte infectivity to mosquitoes [7-11]. Although anemia is an important cause of a male-biased gametocyte sex ratio [12,13], little is known about how malarial anemia influences Plasmodium falciparum gametocyte sex ratios (PfGSR) and transmission in endemic areas of Africa. Such information is necessary to optimize control.

In order to address these issues in an area of intense transmission, we investigated the changes in PfGSR in 1126 consecutive children with acute, symptomatic, uncomplicated falciparum malaria who did or did not have anemia

*Address correspondence to this author at the Department of Clinical Pharmacology, University College Hospital, Ibadan, Nigeria; Tel: +234-8023359390; E-mail: akinsowunmi@ hotmail.com (defined as a hematocrit $<25 \%$ ) in an endemic area of southwest Nigeria. Our aims were to: determine the contribution of anemia to PfGSR on presentation; determine the factors associated with a male biased PfGSR in children who did or did not have anemia on presentation; and evaluate the temporal changes in PfGSR in children following treatment with antimalarial drugs in these children.

\section{PATIENTS AND METHODS}

Patients were recruited from 1999-2006 at the malaria clinic of the University College Hospital in Ibadan, southwest Nigeria, an endemic area of malaria [14], into various antimalarial efficacy studies and were enrolled if the following criteria were met: an age 0.5-14 years, fever or history of fever in the $24-48 \mathrm{~h}$ preceding presentation, pure Plasmodium falciparum parasitaemia $\geq 2000 / \mu 1$ blood, absence of concomitant illness, negative urine tests for 4-aminoquinoline (Dill- Glazko) and sulfonamides (lignin), and written informed consent of a parent or guardian. Patients with severe malaria [15] or serious underlying diseases (renal, cardiac or hepatic) or severe malnutrition were excluded from the study. The studies received approval from the local ethics committee.

Drug treatment was according to standard schedules (Table 1). At enrolment (day 0) and at follow-up on days 1-7, 
Table 1. Treatment Regimens of the Children Enrolled in the Study

\begin{tabular}{|c|c|}
\hline Drugs* & Regimens $\dagger$ \\
\hline \hline CQ & $30 \mathrm{mg} / \mathrm{kg}$ of chloroquine base over 3 days, that is, $10 \mathrm{mg} / \mathrm{kg}$ daily \\
\hline AQ & $30 \mathrm{mg} / \mathrm{kg}$ of amodiaquine base over 3 days, that is, $10 \mathrm{mg} / \mathrm{kg}$ daily \\
\hline PS & Pyrimethamine-sulphadoxine given as $25 \mathrm{mg} / \mathrm{kg}$ of the sulphadoxine component at presentation \\
\hline AS & Artesunate given as $28 \mathrm{mg} / \mathrm{kg}$ over 7 days, that is, $4 \mathrm{mg} / \mathrm{kg}$ daily \\
\hline PSP & Pyrimethamine-sulphadoxine given as in PS above plus probenecid at $20-25 \mathrm{mg} / \mathrm{kg}$ in two divided doses daily for 3 days \\
\hline AL & Artemether (20mg) plus lumefantrine (120mg) given thus: $5-14 \mathrm{~kg}$ received 1 tab., $15-24 \mathrm{~kg}$ received 2 tab., $25-34 \mathrm{~kg}$ received 3 tab., \\
\hline ASAQ & A 34kg received 4 tab. at presentation $8 \mathrm{hr}$ later and at $24,36,48$ and $60 \mathrm{hrs}$ after first dose \\
\hline ASP & Amodiaquine given as in AQ above plus sulfalene-pyrimethamine given as $25 \mathrm{mg} / \mathrm{kg}$ of the sulfalene component \\
\hline
\end{tabular}

* 59, 501, 98, 116, 72, 89, 100 and 91 children were enrolled in CQ, AQ, PS, AS, PSP, AL, ASAQ and ASP groups, respectively.

$\dagger$ All drugs were administered orally.

$\mathrm{CQ}$, chloroquine; AQ, amodiaquine; PS, pyrimethamine-sulphadoxine; AS, artesunate; PSP, pyrimethamine-sulphadoxine plus probenecid; AL, artemether plus lumefantrine; ASAQ, artesunate plus amodiaquine; ASP, amodiaquine plus sulfalene-pyrimethamine.

14,21 , and 28 (up to 2003) and on 1-3, 7, 14, 21, 28, 35 and 42 (after 2003), patients underwent full physical examination and thin and thick blood films examination for quantification of asexual and sexual parasitaemia. Blood was obtained for hematocrit determination on days $0,3,7,14,21,28,35$ and 42 using a microhaematocrit tube and microcentrifuge (Hawksley Lancing, United Kingdom).

Quantification of asexual and sexual parasites in thick films was done against 500 and 1000 leukocytes, respectively assuming a leukocyte count of $6000 / \mu 1$ blood. All gametocytes were sexed if gametocytaemia $\geq 10 / \mu 1$ blood and according to the following criteria [16]: males (microgametocytes) are smaller than females (macrogametocytes), the nucleus is larger in males than females, the ends of the cells are rounder in males and angular in females, with Giemsa the cytoplasm stains purple in males and deep blue in females, and the granules of malaria pigment are centrally located in females and more widely scattered in males. The sex ratio was defined as the proportion of gametocytes in peripheral blood that were male [17]. A gametocyte sex ratio was considered male-biased if it was $\geq 0.5$.

The half-life of gametocyte sex was determined using a non-compartmental pharmacokinetic model as previously described [18,19]. Sex specific half-lives were determined only in patients who had gametocytaemia at enrolment and for at least three times during the first 7-14 days after enrolment and were analyzed only in patients who had a hematocrit value consistently below $25 \%$ or consistently $\geq 25 \%$ during the first 7-14 days of commencing therapy. Gametocyte maleness index (GMI) was defined as the ratio of sex specific half-life male:female. This ratio was determined for patients with or without anemia in each drug treatment group.

\section{DATA ANALYSIS}

Data were analyzed using version 6 of the Epi-Info software [20], and the statistical programme SPSS for Windows version 10.01 [21]. Variables considered in the analysis were related to the densities of $P$. falciparum gametocytes and trophozoites. Proportions were compared by calculating $\chi^{2}$ with Yates' correction or by Fisher exact or by Mantel Haenszel tests. Normally distributed, continuous data were compared by Student's t-tests and analysis of variance (ANOVA). Data not conforming to a normal distribution were compared by the Mann-Whitney U-tests and the Kruskal-Wallis tests (or by Wilcoxon ranked sum test). The relationship between gametocyte sex ratio and clinical or parasitological parameters was assessed by linear regression. A univariate analysis was used to determine the factors, clinical or parasitological, associated with a male biased PfGSR. Because the study was conducted over a period of eight years, time in years since the commencement of the study was included as a dichotomous variable, that is, before 2004 and 2004 onward. All tests of significance were two-tailed. P-values of $\leq 0.05$ were taken to indicate significant differences. Data were (double)entered serially using the patients' codes and were only analyzed at the end of the study.

\section{RESULTS}

\section{Patient Characteristics at Enrolment}

During the study period, 1126 children were enrolled and followed up for at least 21 days. The characteristics of the children with and without anemia are shown in Table 2. Children with anemia were significantly younger, weighed significantly less and had a significantly longer duration of illness.

\section{Therapeutic Responses}

The immediate therapeutic responses are also summarized in Table 2. Fever, but not parasite clearance, was significantly shorter in the non-anemic children.

\section{Gametocyte Carriage and Sex Ratios at Enrolment}

Overall, at enrolment, gametocytes were found in the peripheral blood of 118 children $(10.5 \%)$ (geometric mean gametocyte density $18 / \mu 1$, range 6-366). Overall, $89 \%$ of the 
Table 2. Baseline Characteristics and Immediate Therapeutic Responses of Children with and without Anemia Treated with Antimalarial Drugs

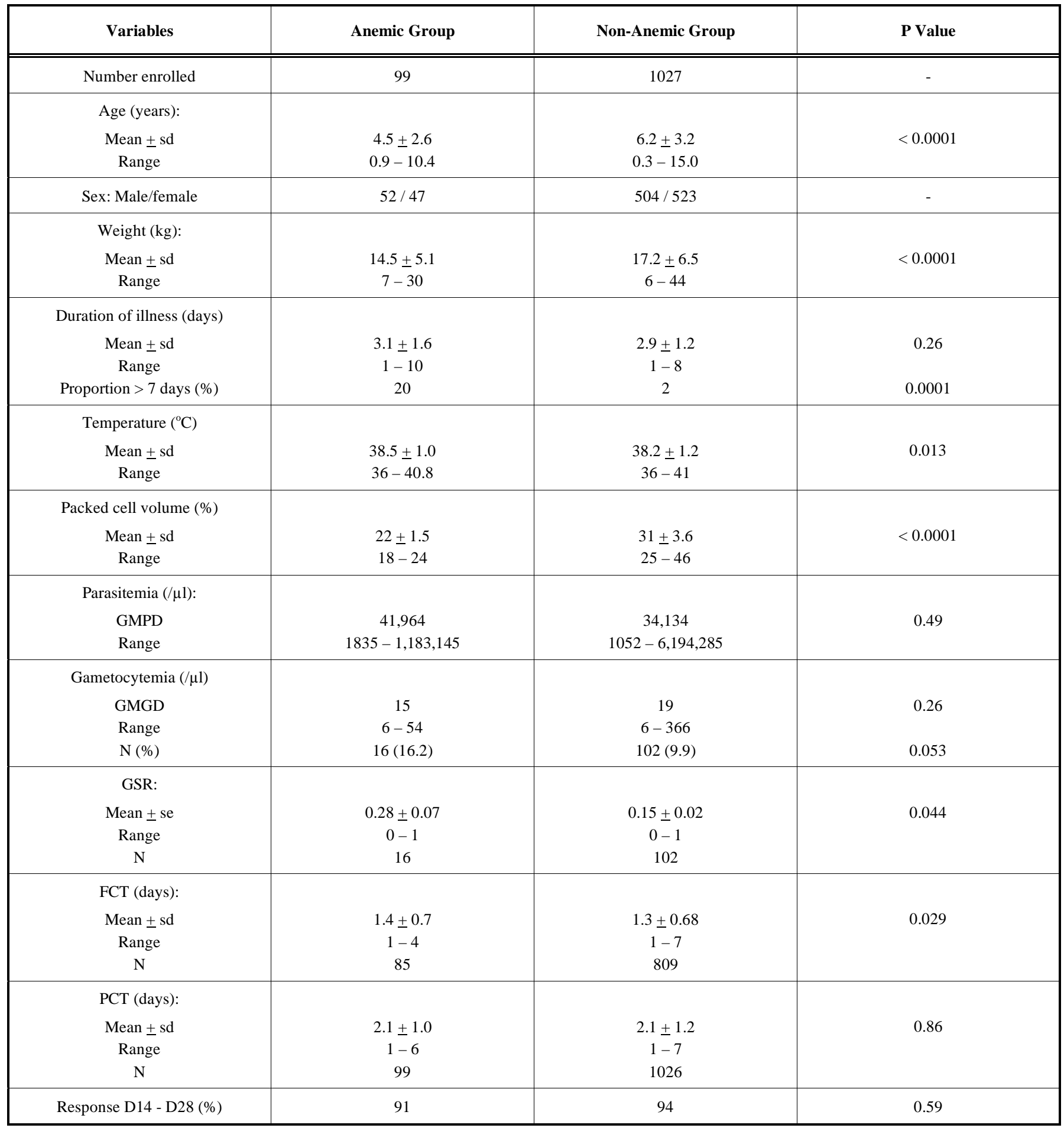

Anemia defined as PCV $<25 \%$.

FCT, fever clearance time; GMPD, geometric mean parasite density; GMGD, geometric mean gametocyte density; GSR, gametocyte sex ratio; PCT, parasite clearance time; N, number; sd, standard deviation; se, standard error of mean.

gametocytes counted could be sexed. Gametocyte carriage was nearly significantly higher in anemic compared to the non- anemic children (16 of $99 v 102$ of $1027, \mathrm{P}=0.053$ ) (Table 2). PfGSR was significantly higher in anemic than non-anemic children $(0.28 \pm 0.07$ (se) $v 0.15 \pm 0.02$ (se), $\mathrm{P}=$ 0.044) (Table 2).
Factors Associated with a male Biased Gametocyte Sex Ratio at Presentation

Table 3 shows that a duration of illness $>3 \mathrm{~d}$ and enrolment before 2004 were significantly associated with a malebiased sex ratio at enrolment in children with anemia. In 
Table 3. Risk Factors for a Male Biased Gametocyte Sex Ratio (gsr) at Presentation in Children with and without Anemia Treated with Antimalarial Drugs

\begin{tabular}{|c|c|c|c|c|c|c|c|c|}
\hline \multirow{2}{*}{ Variables } & \multicolumn{4}{|c|}{ Anemic Group } & \multicolumn{4}{|c|}{ Non-Anemic Group } \\
\hline & $\begin{array}{c}\text { Total } \\
\text { Enrolled }\end{array}$ & $\begin{array}{l}\text { No with } \\
\text { gsr } \geq 0.5\end{array}$ & $\begin{array}{c}\text { OR } \\
(95 \% \mathrm{CI})\end{array}$ & P Value & $\begin{array}{c}\text { Total } \\
\text { Enrolled }\end{array}$ & $\begin{array}{l}\text { No with } \\
\text { gsr } \geq 0.5\end{array}$ & $\begin{array}{c}\text { OR } \\
(95 \% \mathrm{CI})\end{array}$ & P Value \\
\hline \multicolumn{9}{|l|}{ Age (years) } \\
\hline$<5$ & 10 & 3 & 1 & 0.89 & 56 & 17 & 1 & 0.073 \\
\hline \multicolumn{9}{|l|}{ Gender } \\
\hline Male & 9 & 3 & 1 & 0.84 & 51 & 14 & 1 & 0.35 \\
\hline Female & 7 & 2 & $1.2(0.3-5.2)$ & & 51 & 10 & $0.7(0.4-1.5)$ & \\
\hline \multicolumn{9}{|l|}{ Duration of illness (days) } \\
\hline Absent & 3 & 2 & 1 & 0.14 & 40 & 10 & 1 & 0.78 \\
\hline Present & 13 & 3 & $0.3(0.1-1.2)$ & & 62 & 14 & $0.9(0.4-1.8)$ & \\
\hline \multicolumn{9}{|l|}{ Parasitemia $(/ \mu \mathrm{l})$} \\
\hline$<20,000$ & 5 & 2 & 1 & 0.75 & 46 & 9 & 1 & 0.39 \\
\hline$\geq 20,000$ & 11 & 3 & $0.68(0.16-2.9)$ & & 56 & 15 & $1.4(0.7-2.8)$ & \\
\hline \multicolumn{9}{|l|}{ Gametocytemia $(/ \mu \mathrm{l})$} \\
\hline$<20$ & 11 & 4 & 1 & 0.51 & 63 & 15 & 1 & 0.93 \\
\hline$\geq 20$ & 5 & 1 & $0.55(0.1-3.7)$ & & 39 & 9 & $1(0.5-2)$ & \\
\hline
\end{tabular}

* Fever, temperature $>37.5^{\circ} \mathrm{C}$.

CI, confidence interval; FCT, fever clearance time; OR, odds ratio PCT, parasite clearance time.

contrast, only enrolment before 2004 was associated with a male-biased sex ratio in children without anemia.

\section{Relationship between Gametocyte Sex Ratio and Clinical or Parasitological Parameters on Presentation}

Table $\mathbf{4}$ is a summary of the correlation analyses between hematocrit and the clinical and other parasitological parameters in children with or without anemia. In anemic children, there was no significant correlation between hematocrit and clinical or parasitological parameters. In contrast, in children without anemia, hematocrit was positively or negatively correlated with age, duration of illness, weight, parasite density or PfGSR.

\section{Gametocyte Densities before, During, and after Treat- ment with Antimalarial Drugs}

Table $\mathbf{5}$ is a summary of gametocyte densities pre- and post-treatment in anemic and non-anemic children. In both groups of children following treatment with CQ, AQ or PS, post-treatment densities were significantly higher than pretreatment densities but the increases were much more sig- nificant in the non-anemic than the anemic children. In other treatment groups, the number of anemic and non-anemic children was too few to make meaningful conclusions.

\section{Temporal Changes in Gametocyte Sex Ratios Following Treatment}

Following therapy, in 30 and 258 anemic and non anemic children, respectively in whom 5137 and 34481 gametocytes were sexed, respectively, the mean sex ratio was 0.35 (95\%CI $0.19-0.51)$ on day $3,0.63$ (95\% CI $0.47-0.79)$ on day 7 and 0.75 (95\%CI $0.52-0.98)(\mathrm{P}=0.00000003)$ by day 14 after therapy commenced in the anemic group, and 0.36 (95\%CI $0.29-0.43)$ on day 3, 0.72 (95\%CI 0.63-0.81) on day 7 and $0.72(95 \%$ CI $0.64-0.79)(\mathrm{P}=0.00000002)$ by day 14 after therapy commenced in the non-anemic group (Fig. 1a). Fig. (1b) shows the temporal changes in gametocyte sex ratios following treatment with CQ, AQ or ASP. In those treated with CQ or AQ, post-treatment GSR was significantly higher in the anemic than the non-anemic children from days $0-7$ or 14 ( $\mathrm{P}<0.007$ in all cases). In other treatment groups, the number of anemic and non-anemic children was too few to make meaningful conclusions. 
Table 4. Relationship between Hematocrit and Clinical or Parasitological Parameters at Presentation in Children with and without Anemia

\begin{tabular}{|c|c|c|c|c|c|c|}
\hline \multirow{2}{*}{ Variables } & \multicolumn{3}{|c|}{ Anemic Group } & \multicolumn{2}{c|}{ Non-Anemic Group } \\
\cline { 2 - 7 } & Spearman`s rho & P Value & Number & Spearman`s rho & P Value & Number \\
\hline \hline Age & -0.051 & 0.619 & 99 & 0.198 & $<0.0001$ \\
\hline Duration of illness & -0.091 & 0.371 & 99 & -0.114 & $<0.0001$ & 1027 \\
\hline Weight & -0.044 & 0.671 & 99 & 0.242 & -0.0001 & 1027 \\
\hline Temperature & 0.073 & 0.474 & 99 & -0.033 & 0.295 & 1027 \\
\hline Parasitemia & -0.066 & 0.527 & 99 & -0.065 & -0.17 & 0.047 \\
\hline Gametocytemia & 0.3 & 0.26 & 16 & -0.219 & 0.027 & 102 \\
\hline Gametocyte sex ratio & -0.106 & 0.697 & 16 & 102 \\
\hline
\end{tabular}

Table 5. Variations in Gametocyte Density in Children with and without Anemia Treated with Chloroquine, Amodiaquine and Pyrimethamine-Sulphadoxine

\begin{tabular}{|c|c|c|c|c|c|c|c|c|}
\hline \multirow{2}{*}{ Drugs } & \multirow{2}{*}{ Group } & \multicolumn{6}{|c|}{ Days of Follow Up } & \multirow{2}{*}{ P value } \\
\hline & & $\mathbf{0}$ & 1 & 2 & 3 & 7 & 14 & \\
\hline \multirow{2}{*}{ Chloroquine } & Anemic & $\begin{array}{l}10(2) \\
6-18\end{array}$ & $\begin{array}{c}17(2) \\
12-24\end{array}$ & $\begin{array}{c}6(1) \\
6\end{array}$ & $\begin{array}{c}17(2) \\
12-24\end{array}$ & $\begin{array}{c}36(4) \\
6-138\end{array}$ & $\begin{array}{l}15(3) \\
6-42\end{array}$ & 0.01 \\
\hline & Non-anemic & $\begin{array}{l}23(11) \\
6-150\end{array}$ & $\begin{array}{l}21(10) \\
6-132\end{array}$ & $\begin{array}{l}23(12) \\
6-138\end{array}$ & $\begin{array}{l}16(14) \\
6-150\end{array}$ & $\begin{array}{l}19(19) \\
6-188\end{array}$ & $\begin{array}{l}17(14) \\
6-102\end{array}$ & $<0.0001$ \\
\hline \multirow{2}{*}{ Amodiaquine } & Anemic & $\begin{array}{l}19(8) \\
6-54\end{array}$ & $\begin{array}{l}19(8) \\
6-324\end{array}$ & $\begin{array}{l}101(4) \\
6-600\end{array}$ & $\begin{array}{c}45(8) \\
6-798\end{array}$ & $\begin{array}{c}50(6) \\
12-558\end{array}$ & $\begin{array}{l}26(4) \\
6-180\end{array}$ & 0.019 \\
\hline & Non-anemic & $\begin{array}{l}16(44) \\
6-288\end{array}$ & $\begin{array}{l}17(36) \\
6-648\end{array}$ & $\begin{array}{l}17(35) \\
6-552\end{array}$ & $\begin{array}{l}20(49) \\
6-720\end{array}$ & $\begin{array}{l}25(32) \\
6-600\end{array}$ & $\begin{array}{l}11(20) \\
6-108\end{array}$ & $<0.0001$ \\
\hline
\end{tabular}

Values are geometric mean (number), range.

\section{Influence of Drug Treatment on the Half-Life of Game- tocyte Sexes}

We estimated, using a non-compartment model, the halflife of gametocyte sexes in all treatment groups. Table 6 shows that ratio of the sex specific half life male:female, the 'gametocyte maleness index' (GMI), in anemic and nonanemic children treated with CQ, AQ and PS. In general, GMI in anemic children was one and a half to two folds higher than in non-anemic children.

\section{DISCUSSION}

In this study, the overall 'anemia rate', defined as hematocrit less than $25 \%$, in children with acute falciparum malaria was $9 \%$. This rate is considerably lower than $40 \%$, were a hematocrit less than $30 \%$ were used in this cohort of children. Our justification for the cut off was based on recent studies that showed a hematocrit less than $25 \%$ was a predictor of a male-biased PfGSR in malarious children from this endemic area [22]. Overall, the gametocyte carriage rate of $16 \%$ in anemic children was almost significantly higher than the $10 \%$ in the non-anemic group (Table 2). This would suggest anemia predisposes these children to gametocyte carriage and supports finding from others areas of Africa and elsewhere [5,23]. Submicroscopic gametocytaemia, detectable by polymerase chain reaction (PCR), is not uncommon in children undergoing antimalarial therapy $[11,24]$. Therefore, our overall estimates of gametocyte carriage in anemic and non-anemic children are likely to be underestimates.

In this study, the overall sex ratio at enrolment was 0.18 , in keeping with natural population [12] but PfGSR was twice as high in the anemic as the non-anemic children. Since a higher PfGSR increases the chances of mosquito infectivity 
A

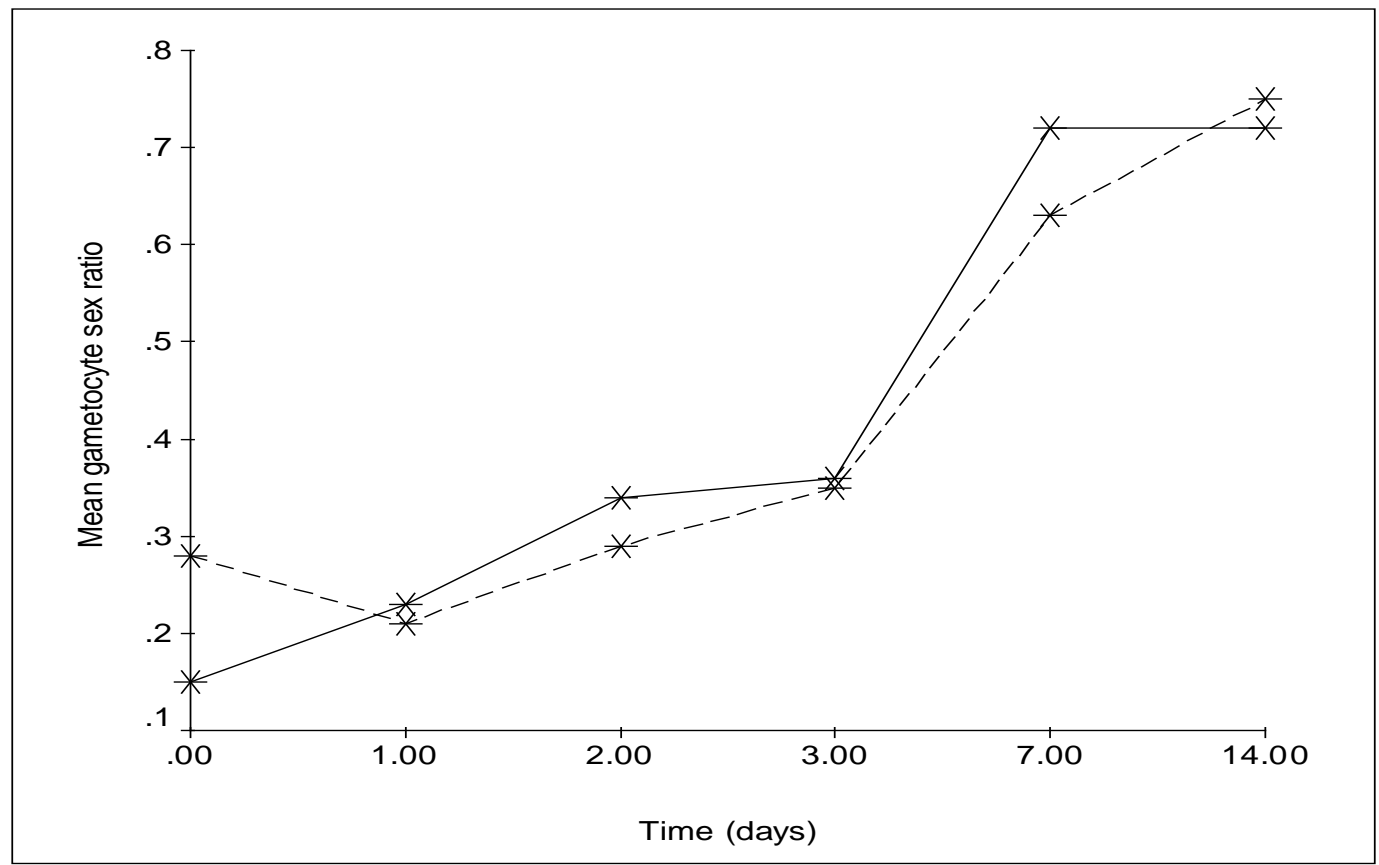

B

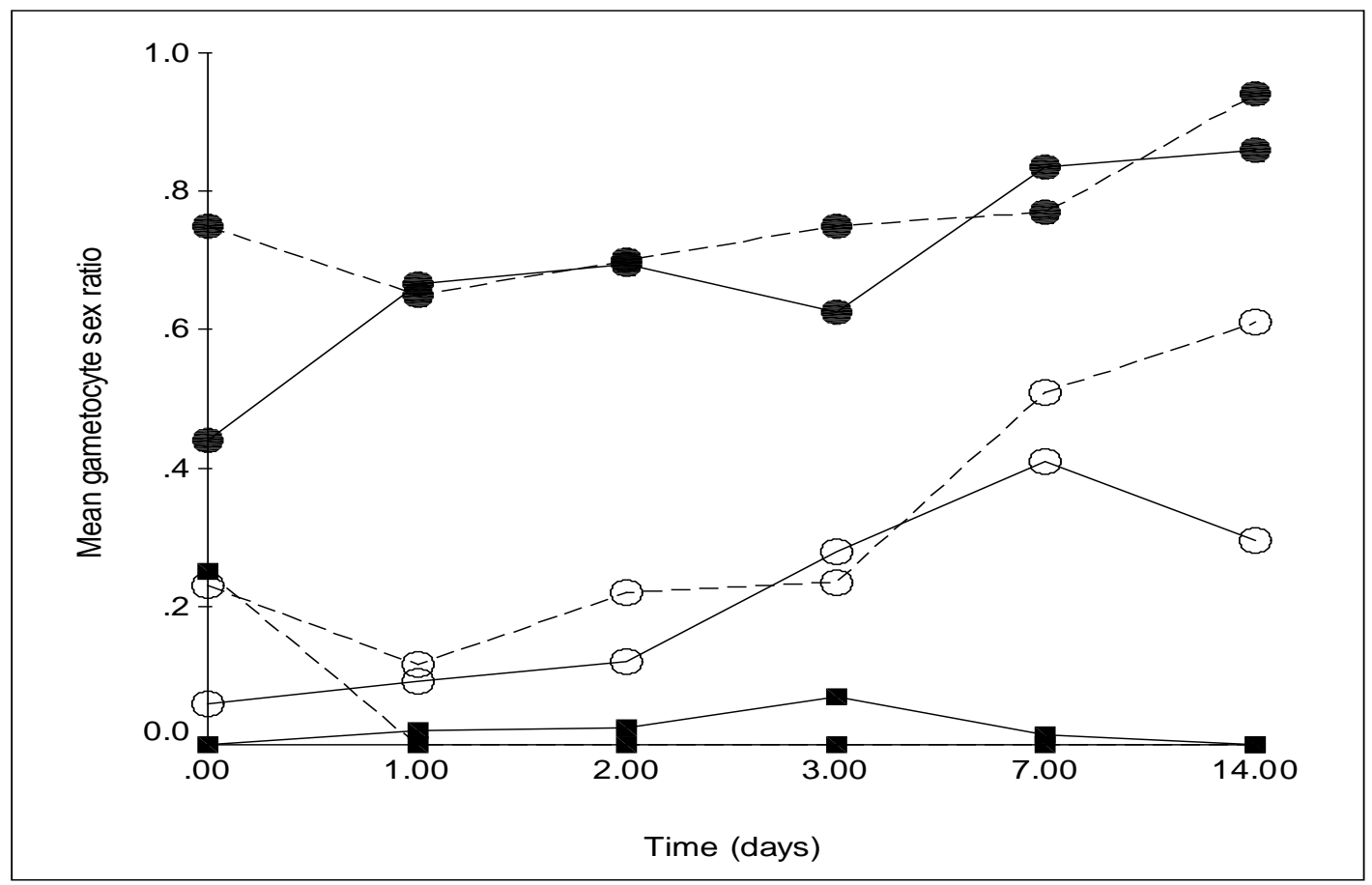

Fig. (1). Variations in overall gametocyte sex ratio in anemic (broken line) and non-anemic (solid line) (A), and in the gametocyte sex ratio of children treated with chloroquine $(\bullet)$, amodiaquine $(\mathrm{O})$ and amodiaquine-sulfalene-pyrimethamine $(\boldsymbol{\bullet})(\mathbf{B})$.

[8], this would suggest anemic children are at higher risk of infecting mosquitoes. In addition, the higher gametocyte carriage rate in anemic children may mean that they constitute a larger reservoir of infection than the non-anemic children. Taken together, both factors may enhance transmission of infection by anemic children in the population. The reasons for the higher PfGSR in anemic children are not readily apparent from our results, but erythropoietin levels have been shown to increase the sex ratio in animals [12]. Studies comparing the kinetics of the secretion and elimination of erythropoietin in anemic and non-anemic African children are urgently needed.
The factors associated with a male biased PfGSR in anemic and non-anemic children were similar. However a longer duration of illness was associated with a male biased PfGSR in anemic children. The reasons for this are unclear. In natural infections in animals sex ratio often increase over the course of infections $[12,25]$. Since a longer duration of illness is a predictor of anemia in malaria [26], it would appear the relatively longer duration of the untreated infections in anemic children allow a faster progression of a natural change of increase in PfGSR. The lack of correlation between hematocrit and PfGSR in anemic children and the significantly negative correlation in the non-anemic children, 
Table 6. Gametocyte Maleness Index (GMI) in Children with and without Anaemia Treated with Chloroquine, Amodiaquine and Pyrimethamine-Sulphadoxine

\begin{tabular}{|c|c|c|c|c|c|c|}
\hline \multirow{2}{*}{ Gametocyte } & \multicolumn{2}{|c|}{ Chloroquine } & \multicolumn{2}{|c|}{ Amodiaquine } & \multicolumn{2}{|c|}{ Pyrimethamine-sulphadoxine } \\
\hline & Anemic & Non-Anemic & Anemic & Non-Anemic & Anemic & Non-Anemic \\
\hline \multicolumn{7}{|l|}{ Microgametocyte } \\
\hline Mean & 0.65 & 0.89 & 1.3 & 0.79 & 1.63 & 0.78 \\
\hline$(95 \% \mathrm{CI})$ & $(-0.02-1.32)$ & $(0.8-0.98)$ & $(0.008-2.6)$ & $(0.58-1.0)$ & $(-10-13.5)$ & $(0.22-1.32)$ \\
\hline Number & 3 & 5 & 6 & 9 & 2 & 3 \\
\hline \multicolumn{7}{|l|}{ Macrogametocyte } \\
\hline Mean & 0.22 & 0.47 & 0.64 & 0.66 & 0.6 & 0.69 \\
\hline$(95 \% \mathrm{CI})$ & $(-0.57-1)$ & $(-0.23-1.17)$ & $(0.34-0.94)$ & $(0.46-0.87)$ & $(-2.5-3.72)$ & $(0.03-1.34)$ \\
\hline
\end{tabular}

CI, confidence interval.

suggest that, in this cohort of children, the critical haematocrit threshold producing 'all or none effect' on GSR was a value below $25 \%$.

Following therapy, in general, the temporal changes in PfGSR were similar in anemic and non-anemic children: both gametocyte densities and PfGSR increased significantly. This could be explained by the fact that in both groups, drug treatment increased both gametocyte density, and contributed equally to the increase in PfGSR. However, the background effect of anemia on PfGSR was still evident in patients treated with chloroquine, and amodiaquine. In this subgroup of patients, following therapy, PfGSR was significantly elevated in the anemic than in the non-anemic group for up to7-14 days.

In an attempt to discern the mechanism(s) of the anemiainduced increases in PfGSR, we determined the half-life of gametocyte sexes. In the present study, the gametocyte maleness index in anemic children was one and a half to two folds greater than in non-anemic children treated with similar drugs. This would suggest anemia preferentially prolonged the half- life of male gametocytes perhaps by encouraging their release into, and survival in the circulation. There are advantages in using the GMI: it allows assessment of the effects of each drug on gametocyte sexes; its application is independent of any definition of a male-biased sex ratio; it is a summation of several processes- drug, parasite and patient factors; it may be used to evaluate the effects of other factors on gametocyte sex ratios.

The study has several limitations that should be addressed in future studies. First, the study did not evaluate other potential association of male-biased PfGSR such as history of antimalarial drug use. Some antimalarials, for example, antifolates may produce a male biased PfGSR [27]. Second, anemia is often multi-factorial [1,3]. In this regard the contribution of co-infection with helminths to the anemia of malaria was not evaluated. In addition, co-infection with helminths may be associated with increased gametocyte carriage [28]. Another limitation was the levels of erythropoietin in the individual patients were not measured making it difficult to relate the levels directly to PfGSR.

There are potential applications of our findings: In addition to other causes, anemia in falciparum malaria is related to antimalarial drug resistance and treatment failure [26]. Therefore, prompt treatment of acute malaria infections with effective non-anemia and non-gametocytaemia-inducing drugs such as the artemisinin derivatives $[19,22,29,30]$ should reduce the burden of malarial anemia; community control of infections and anemia should reduce the risk of gametocyte carriage and a male biased PfGSR and burden of malaria transmission.

\section{ACKNOWLEDGEMENTS}

The antimalarial efficacy studies from which the sex ratio studies were derived received financial support from The UNDP/World Bank/ WHO Special Programme for Research and Training in Tropical Diseases through the Career Development Grant awarded to AS. The AL and ASP efficacy study received financial support from Pfizer Global Pharmaceuticals. We thank our clinic staff, especially Moji Amao, Adeola Alabi, and Bose Shoyoye for assistance with running the studies.

\section{REFERENCES}

[1] Crawley J. Reducing the burden of anemia in infants and young children in malaria-endemic countries of Africa: from evidence to action. Am J Trop Med Hyg 2004; 71: 25-34.

[2] Hedberg K, Shaffer N, Davachi F, et al. Plasmodium falciparum associated anemia in children at a large urban hospital in Zaire. Am J Trop Med Hyg 1993; 48: 365-71.

[3] Nkuo-Akenji TK, Chi PC, Cho JF, et al. Malaria and helminth coinfection in children living in a malaria endemic setting of mount Cameroon and predictors of anemia. J Parasitol 2006; 92: 1191-5. 
[4] Akim NIJ, Drakeley C, Kingo T, et al. Dynamics of Plasmodium falciparum gametocytaemia in symptomatic patients in an area of intense transmission in Tanzania. Am J Trop Med Hyg 2000; 63: 199-203.

[5] von Seidlein L, Drakeley C, Greenwood B, et al. Risk factors for gametocyte carriage in Gambian children. Am J Trop Med Hyg 2001; 65: 523-6.

[6] Sowunmi A, Fateye BA, Adedeji AA, et al. Risk factors for gametocyte carriage in uncomplicated falciparum malaria in children. Parasitology 2004; 129: 255-62.

[7] Tchuinkam T, Mulder B, Dechering K, et al. Experimental infections of Anopheles gambiae with Plasmodium falciparum of naturally infected gametocyte carriers in Cameroon: factors influencing the infectivity to mosquitoes. Trop Med Parasitol 1993; 44: 271-6.

[8] Robert V, Read AF, Essong J, et al. Effects of gametocyte sex ratio on infectivity of Plasmodium falciparum to Anopheles gambiae. Trans R Soc Trop Med Hyg 1996; 90: 621-4.

[9] Robert V, Awono-Ambene HP, Le Hesran J-Y, et al. Gametocytemia and infectivity to mosquitoes of patients with uncomplicated Plasmodium falciparum malaria attacks treated with chloroquine or sulfadoxine plus pyrimethamine. Am J Trop Med Hyg 2000; 62: 210-6.

[10] Hogh B, Gamage-Mendis A, Butcher GA, et al. The differing impact of chloroquine and pyrimethamine/sulfadoxine upon the infectivity of malaria species to its vector. Am J Trop Med Hyg 1998; 58: 176-82.

[11] Bousema JT, Schneider P, Gougna LC, et al. Moderate effect of artemisinin based combination therapy on transmission of Plasmodium falciparum. J Infect Dis 2006; 193: 1151-9.

[12] Paul REL, Coulson TN, Raibaud A, et al. Sex determination in malaria parasites. Science 2000; 287: 128-31.

[13] Robert V, Sokhna CS, Rogier C, et al. Sex ratio of Plasmodium falciparum gametocytes in inhabitants of Dielmo, Senegal. Parasitology 2003; 127: 1-8

[14] Salako LA, Ajayi FO, Sowunmi A, et al. Malaria in Nigeria: a revisit. Ann Trop Med Parasitol 1990; 84: 435-45.

[15] World Health Organization. Severe falciparum malaria. Trans R Soc Trop Med Hyg 2000; 94 (Suppl 1): 1-90.

[16] Carter R, Graves PM. In: Wernsdorfer WH, McGregor I Eds., Malaria: Principles and Practice of Malariology, Edingburgh, Churchill Livingstone. 1988; vol I: 253-303.

[17] Pickering J, Read AF, Guerrero S, et al. Sex ratio and virulence in two species of lizard malaria parasites. Evol Ecol Res 2000; 2: 17184.
[18] Sowunmi A, Fateye BA. Plasmodium falciparum gametocytaemia in Nigerian children: before, during and after treatment with antimalarial drugs. Trop Med Int Health 2003; 8: 783-92.

[19] Sowunmi A, Balogun T, Gbotosho GO, et al. Activities of amodiaquine, artesunate, and artesunate-amodiaquine against asexualand sexual-stage parasites in falciparum malaria in children. Antimicrob Agents Chemother 2007; 51: 1694-9.

[20] Epi Info Version 6. A Word Processing Data Base and Statistics Program for public Health on IBM-compatible Microcomputers. Atlanta, GA, Centers for Disease Control and Prevention. 1994.

[21] SPSS for Windows Release 10.01 (Standard Version). Chicago, IL, SPSS Inc. 1999

[22] Sowunmi A, Balogun ST, Gbotosho GO, et al. Plasmodium falciparum gametocyte sex ratios in symptomatic children treated with antimalarial drugs (Acta Tropica, under review)

[23] Price R, Nosten F, Simpson JA, et al. Risk factors for gametocyte carriage in uncomplicated falciparum malaria. Am J Trop Med Hyg 1999; 60: 1019-23.

[24] Shekalaghe SA, Bousema JT, Kunel KK, et al. Submicroscopic Plasmodium falciparum gametocyte carriage is common in an area of low and seasonal transmission in Tanzania. Trop Med Int Health 2007; 12: 547-53.

[25] Drew DR, Reece SE. Development of reverse-transcription PCR techniques to analyse the density and sex ratio of gametocytes in genetically diverse Plasmodium chabaudi infections. Mol Biochem Parasitol 2000; 156: 199-209.

[26] Price R, Simpson JA, Nosten F, et al. Factors contributing to anemia after uncomplicated falciparum malaria. Am J Trop Med Hyg 2001; 65: 614-22.

[27] Sowunmi A, Fateye BA, Adedeji AA, et al. Effects of antifolatescotrimoxazole and pyrimethamine-sulfadoxine on gametocytes in children with acute, symptomatic, uncomplicated Plasmodium falciparum malaria. Mem Inst Oswaldo Cruz 2005; 100: 451-5.

[28] Nacher M, Singhasivanon P, Silachamroon U, et al. Association of helminth infections with increased gametocyte carriage during mild falciparum malaria in Thailand. Am J Trop Med Hyg 2001; 65: 644-7.

[29] Chotivanich K, Udomsangpetch R, Dundrop A, et al. The mechanism of parasite clearance after antimalarial treatment of Plasmodium falciparum malaria. J Infect Dis 2000; 182: 629-33.

[30] World Health Organization. Antimalarial drug combination therapy. Report of a WHO Technical Consultation. Document WHO/ CDS/RBM/2001.35. WHO, 2001. Geneva.

(C) Sowunmi et al.; Licensee Bentham Open.

This is an open access article distributed under the terms of the Creative Commons Attribution License (http://creativecommons.org/licenses/by/2.5/), which permits unrestrictive use, distribution, and reproduction in any medium, provided the original work is properly cited. 